\section{Issues in Informing Science + Information Technology}

Volume 15, 2018

\title{
Changes in Public Institutions as a FunCtion of TECHNOLOGY AND ITS IMPACT ON SOCIETY
}

Josueth Meza
SENESCYT - Coordinacion Zonal ! y 2

Universidad Técnica del Norte, Ibarra, Ecuador jameza@utn.edu.ec

\section{AbSTRACT}

Aim/Purpose

Background

Methodology

Contribution

Findings

Recommendations for Practitioners

Recommendation for Researchers Impact on Society

Future Research

Keywords
The purpose of this article is to establish the different impacts of technological changes in institutions generating irrevocable changes in today's society.

Technological changes have had a positive impact on many aspects of everyday life today, and it is natural that both public and private institutions benefit from this reality.

\section{The research method used is based on the explanatory approach, through the} documentary review of secondary sources and research works.

The implementation of electronic government in Ecuador is presented as a direct consequence of these technological developments with ways to direct and govern a country, which leads to competitive advantages in a world that is increasingly globalized.

In the institutions the only permanent thing is change, for which the changing and evolving fact that the public and private institutions of today must have is highlighted.

Results can inform to users the importance of the "new government" in a practical level.

The influence of technology on how to govern and if this in some way improves the functioning of the State.

Technological developments, which leads competitive advantages in a world that is increasingly globalized.

Create discussion and have a starting point to compare the influence of technological government in different parts of the world.

technological changes, electronic government, information and communication technology

Accepting Editor: Eli Cohen | Received: February 13, 2018 | Revised: March 13, 2018 | Accepted: April 2, 2018.

Cite as: Meza, J. (2018). Changes in public institutions as a function of technology and its impact on society. Issues in Informing Science and Information Technology, 15, 145-156. https://doi.org/10.28945/4034

(CC BY-NC 4.0) This article is licensed to you under a Creative Commons Attribution-NonCommercial 4.0 International License. When you copy and redistribute this paper in full or in part, you need to provide proper attribution to it to ensure that others can later locate this work (and to ensure that others do not accuse you of plagiarism). You may (and we encourage you to) adapt, remix, transform, and build upon the material for any non-commercial purposes. This license does not permit you to use this material for commercial purposes. 


\section{INTRODUCTION}

Society in general has been in constant evolution since creation. When reference is made to information and access to it, this has brought incredible growth, which was achieved at an incalculable rate of change. The estimation of this information stored in its entirety, from the beginning of civilization until the year 2003, is about five Exabyte (1 Exabyte is equivalent to one million terabytes). Today however, with technological advances it occurs in a couple of days.

Lusting (Pugh, 1995), expert in the development, deployment, and maintenance of applications of IBM ILOG CPLEX, mentions that "Solution methods are currently 10,000 times faster than those used 15 years ago". Example of this is the delay time of an email (only a few seconds) in comparison with postal mail arriving at the destination, which takes days.

It should be noted that technological change is characterized by the introduction of variations that lead to the incorporation of new technologies: forms of use, replacement of products derived from it, processes, design, techniques, new regulations, etc. As a result of the invention, innovation, transfer, and dissemination of these new technologies, the main purpose is aimed at solving problems in both public and private sectors. This has been accomplished in order to generate impact from the different social, economic and political dimensions.

Progressive technological change has been introduced and transformed as individuals think through ways of doing things, manage their time, and achieve their goals. In society, there has been exponential growth in the different fields of knowledge. The main characteristic has been to generate influence in one or more fields which affects the organizational behavior in terms of decision making by the responsible persons in a diversity of institutions.

One change with the greatest impact in recent times is within the Information and Communication Technologies. As a general concept, this refers to the use of multiple technological or computer media to process, disseminate, and store all types of information via digital and visual with different purposes to manage, organize, and above all coordinate various work, academic, research, etc.

In the decade of the 1970s, Computer Science consolidated the change of paradigm and brought with it consequences in which professionals were beginning to experience variations - in relation to the systems and storage of information. It can be likened to an explosion, crossing and intersecting at the managers' desk with a huge amount of data.

That is why, according to the above, the following questions arise in terms of technological changes and production of information: Is the human being ready to handle a high flow of information within their reach? In addition, accessibility to the information and the use of it can be used to manage institutions in a more efficient and effective way? Now with the presence of technology and its high growth, social impact must be understood, specifically in governments. Eliminating bureaucracy and the pursuit of the improvement of nations, these are the main factors to be achieved. To accomplish what is now called electronic government with the application of Information and Communication Technologies (ICT) (Mejia \& Muñoz, 2017) will be in the operation of the public sector, the objective being to increase efficiency, transparency, and citizen participation (according to the Organization of American States). Conjugating this e-government within the various forms of existing governmental management allows formulation of another question to answer: Is technology the headmaster of the new institution?

It should be noted that when mentioning the use of information and communication technologies, they represent instruments that facilitate the exchange of data in its different modalities, so that it can be seen or read by the recipient of information. ICT is the means that allows the automation of activities carried out both in public and private institutions, in the manufacture of a product or the provision of a service. 


\section{THEORETICAL BACKGROUND}

\section{NATURE OF TECHNOLOGICAL CHANGE}

Thanks to technology, civilization has managed to develop even more because its link with science has been strengthened. Being part of the culture, technology has facilitated the development of many organizations and society in general through finance, manufacturing, many facets of work commercialization, and the maintenance of the current world (Mejia \& Muñoz, 2017).

Technology originated from man's experience with the properties of all things and techniques to manipulate them, experiment with past practical knowledge, and share information from generation to generation. With that accumulated knowledge, a whole additional language developed that describes, sets standards, and allows further contributions to technology. This assimilation and understanding of the underlying principles in how things behave forms a newer and more advanced scientific perspective.

Computer Science has become a discipline that uses specific knowledge to estimate what will be the behavior of things before executing and observing them. In addition to this science, new types of behavior are required to make way for new technologies, the CS Engineer being the main designer for the resolution of practical problems, making use of the interrelation (science and technology) and employing design strategies.

The computer, for example, has allowed solving problems in various areas of knowledge, which would not have been possible otherwise. Technology is essential for the effect of measurements, data collection, sample processing, computing, and communication, among others. The development of new instruments and techniques through technology is increasing, which continues the progress and advancement of technology and scientific research.

To the extent that technologies have become more complex, scientific interrelationships are strengthened. Within physics, the ability to experiment and to study the outcome being interdependent requires, first, a new understanding and simultaneously that new research often needs a recent technology that can be developed via Computer Science.

CS Engineering is the technological component that has a close link with scientific research and mathematical models. The purpose being to analyze the problem, formulate a solution, form a general view, then concentrate on the design of technical details, focusing on the construction of the object (chip of a computer, a car engine, etc.) or processes as in a product test.

Individual inventiveness is essential in technological innovation. However, social and economic forces have a decisive influence on which technologies will be developed, which will be paid attention to, invested in, or used. Such decisions are taken directly as a matter of government policy and indirectly as a consequence of the circumstances and values of a society at a particular time. The degree of social acceptance that this technological innovation will have depends on multiple factors such as availability of capital, budget, national and local regulations, and consumer acceptance, among others.

Technology has significantly influenced the course of history and the nature of human society (Soto, 2012) and continues to do so. The great evolutions in agricultural technology, for example, have perhaps had more influence on the way of life of people than political revolutions; changes in health and preventive medicine have contributed to the population explosion (and its control). Gunpowder and nuclear explosives evolving from arcs and arrows have in turn changed the way war is waged. And the microprocessor is changing the way individuals write, calculate, perform banking, manage business, conduct an investigation, and communicate with each other. Technology has made possible large-scale changes, such as the increasing urbanization of society and the enormous growth of the economic interdependence of communities around the world. 
Historically, some social theorists believed that technological change, such as industrialization and mass production, would cause social change. Others however, thought that political and religious changes would lead to social change. It is clear that, due to the communication network between social and technological systems, many influences act in both directions.

\section{SOCIAL DimENSION OF TECHNOLOGICAL CHANGE}

Technological change is associated with new developments or technological equipment in such a way that there is a new way of use, new regulations, and new products. These novelties can be developed, copied, adopted, sold, bought, but, whatever their form of acquisition, to achieve their relevance in the place where they have been implemented, they must necessarily be socially constructed.

In this sense it is necessary to carefully consider the contributions of the new sociological interpretation of technological change. The most important thing to highlight in these new interpretations is that their authors are focused on showing how technology itself can be understood as a cultural product that cannot be abstracted from the social and cultural forces that create or use it, in its own words, build and model. In fact, this social dimension is what often guides the direction that technological changes should take. In this context, according to Douglas (2012), Thomas P. Hughes proposes the concept of technological systems composed of disordered and complex components for solving problems.

Parayil (1991) defines technological change as a temporary and cumulative process, which increases the ability of groups to solve their social, economic and daily problems. The central element of the concept is the knowledge, and it is the basis of the process of technological change. This cognitive process involves changes in structure and content, and in the context of production of technological knowledge. While the manifestation of change is tangible and apparent in the form of material artifacts, the integral part of this process is cognitive in nature.

According to Parayil (1991), technological change can be analyzed from three complementary angles: from its trajectory determined by political, economic and social interests; from its nature, which is dictated by the cultural and cognitive attributes of the members of the social group involved; and from its internal dynamics, which is determined by the functional attributes of technology.

\section{IMPLICATIONS OF TECHNOLOGICAL CHANGE}

Among the great challenges that arise in the use of technology as a competitive advantage within organizations is to adapt to human needs at the speed of the technological innovations that are being developed. For this, it is necessary to successfully educate the users to enhance their feelings of accomplishment in learning the technological changes necessary to interact with the new beginnings of e-government. If it is true that there are technological changes that generate real revolutions in society, as we saw in the previous section, it is also true that participation can be a determining factor in adoption processes.

If an adequate relationship scheme is not built between the change agent, the users, the beneficiaries, and the environment, the greatest benefit that can be obtained from technological change in the organization will not be achieved. That is why it is important to review the implications that technological change has had on each of these factors.

\section{Impact of technological change}

The impact of technological change on organizations and their culture is what the theories of technical partner systems are based on. In these systems, there are continuous interactions between human groups and technology. It is known that changes in the technical or technological system must necessarily be accompanied by social changes in the organization. Discrepancies in that sense can only lead to failure. An adequate intervention in organizational development can diminish the impact of changes and position the organization towards a higher development platform. 
The work done by Joan Woodward (1955) is a classic example of how both systems are related. Three main types of technology were observed:

- Small-scale production, in which products or services made to the measure and taste of the consumer are elaborated. For example, the work of an architect or the configuration of a computer network.

- Large-scale production such as that found in continuous assembly lines. An example of this would be an automotive factory.

- Process production, which involves the transformation of raw material through a continuous series of automated processes. For example, the work that is done in an oil refinery or a nuclear power plant.

From Woodward's work (1955), it is concluded that the organizational culture associated with each type of technology is essentially different, resulting in both the unitary and process technology, in consequence a more organic culture. Therefore, with high levels of adaptation and evolution and less formalization of behavior, greater decentralization can be attained. While the change in large-scale production is more mechanical, greater formalization of behavior with attention more focused on production and efficiency is consequently realized.

Due to changes in computer technology today, we are talking about cyber culture, understood by Woodward as a "set of techniques, in the ways of being, of doing, of values, of representations, which are related to the extension of Cyberspace". This neologism combines the word culture and the prefix cyber in relation to cybernetics. Observing cyber culture in three ways:

1. Interactivity: what is the relationship between the person and the digital environment defined by the hardware that connects them to both.

2. Hyper textuality: what is interactive access to any information from anywhere. It is a new condition of storage and delivery of contents.

3. Connectivity: what is powered by technology, for example, the Internet.

Organizations increasingly require the establishment of a related culture, the technological means available and that are in accordance with the technical systems that are available. In this way, those who do not adapt or fundamentally do not take advantage of the resources offered by the new technology are considered "technological illiterates". For those individuals, it will be increasingly difficult to compete.

\section{Impact at work}

Different studies (Sánchez, 2012; Soto, 2012) reveal that the tendency to work at a distance, also known as teleworking, is in full growth. To understand this in number, in Latin American countries in 2003 some 500,000 people per country worked from home at least once per week. In 2014 the number of teleworkers rose to two million people, that is, in a decade the figures quadrupled. It is currently estimated that more than 4 million people in Latin America are engaged in this type of activity.

A British company known as "British Telecommunications" was one of the first organizations to offer this to its workers. Beginning with a program of work at home in 1986, the company managed to annex 15,000 workers from home out of a total of 92,000 employees. The company argues that each teleworker saves the company approximately $\$ 9,000$ per year and additionally experienced a $20 \%$ increase in productivity. A side benefit was fewer sick days per employee.

In Ecuador, it is increasingly common to work from home or from sites designed especially for remote work. It is also common for Ecuadorian professionals to work remotely for firms outside the country, which translates into an interesting source of export service to the nation. Consequently, a new generation of young professionals has made a change in their way of working. 
Gradually, the paradigm based on schedule compliance, having the professional in an office cubicle and predominantly vertical leadership has begun to be questioned. Additionally, the better the professional is prepared, the more competitive he will feel and therefore more self-confident. This type of teleworking ends up being a good argument to attract qualified professionals.

\section{Impacts on the structures}

The organizations also show the need to carry out a contingency administration (Arteaga, Medellin, \& Santos, 1995), where the structures vary according to the technical system used. The number of hierarchical levels and control points are not only associated with the technical system used but also the business functions that vary in importance, since within organizations with unitary systems, the most important roles are product development and project design. On the other hand, in the production of scale, the search for efficiency in the process prevails finally in the automated process. The main function is the marketing which includes relations with customers.

These levels of hierarchy of the pyramid are also impacted. When manual labor within the organization decreases it allows human talent, even at the lowest level, to become professional. In addition to this, in terms of accessibility of information, decision making from the managerial point of view flows throughout the organization. As a result, the decrease of said levels and a flattening of hierarchical structures are generated with the consequent enlargement of the control points.

Another evident trend in current structures is the outsourcing of the service, modifying departmental structures, especially those related to systems management, which undergo continuous changes in their functions and ways of operating.

\section{Impact on economic effects}

In a progressive manner, costs in transaction processing and communication are reduced. As costs descend, organizations increase investments in the area of information technology and communications. Therefore, they are better prepared to reduce their working capital, improve management of inventory information and their relationship with suppliers, customers and cash flow.

\section{Impact on the processes}

It is clear that the automation of processes has represented a revolution, especially in factories and warehouses of materials and finished products, all as a result of the use of robotic technology. This development has radically transformed the system, even beyond of the limits of the organization. The development of technological systems, in particular IT (information technology), has favored the management of the various value chains, benefiting the practice of Just in Time (JIT) and the coordinated work between suppliers and customers along the Logistics chain. As a result, all this simplification that takes place in the value chain generates an increase in profits and a reduction in costs, which translates into an increase in its competitiveness as an organization.

\section{Impact on behavior}

As has been mentioned before, as a result of the technological change in the processes, the professional levels are those that prevail in these organizational structures. Hence, the structures increasingly adopt configurations related to professional bureaucracies where the knowledge and innovation of those who integrate it are privileged, being handled in an open and participatory manner with strict

follow-up in the fulfillment of the objectives set. Vertical and horizontal decentralization is characteristic of these configurations.

When you take advantage of knowledge and teamwork, it is a characteristic of organizations, where the emphasis placed is on the training of their collaborators. Therefore, it is usual that the management systems by objectives include goals in this sense. 


\section{Impact on information systems}

Undoubtedly, one of the competitive weapons at the first level for any organization is information. It is impossible to undertake any strategic planning without having the necessary external information. Also, it cannot be efficient within the different processes, such as administration, production and distribution if you do not have enough information.

This is where technological change, perhaps, has had the greatest impact on all organizations, as it provides adequate tools to achieve good administration, because it facilitates obtaining information and not only in the search but in managing it more easily, in such a way that it must be able to measure those qualities, which are difficult to measure (employee satisfaction, work environment, etc.)

Therefore, the information and the capacity that the organization has through technological means, allows it to compile and interpret all the information in an applicable way with an additional benefit, the management of these tools develops a competitive strategy.

\section{Impact on communications}

With the change of technology, communications have changed diametrically and allowed the establishment of relationships previously unthinkable in the past. In fact, upper-level management of large companies has direct dialogue with all its employees even at lower levels of the organization. Managers can communicate throughout the organization without filters. This openness of communication breaks barriers, allows teamwork and, ultimately, allows organizations to be more efficient.

Another fundamental aspect that the advance in communications has allowed is the implementation of distance education and medicine; already these are concrete realities in our society.

Undoubtedly, in the presence of so much information and communication openness, it leads organizations to a new challenge, which is the protection of personal data of those who work with it, along with the additional challenge of protecting corporate information involving its strategic nature of operations.

\section{THE TECHNOLOGICAL CHANGES, INTERNET AND ELECTRONIC GOVERNMENT}

Technological changes currently depend on the development of new and improved innovations and upgrades to these changes, generating a direct impact on the socio-economic development of the countries. Important to remember is that Information and Communication Technologies (ICT) represent a useful tool.

ICTs are defined as technological devices (hardware and software) that allow editing, producing, storing, exchanging, and transmitting data between different information systems that have common protocols. These tools play a substantive role in the generation, exchange, dissemination, management, and access to knowledge (Cobo, 2009).

Currently, with the infrastructural deployment of knowledge, through the use of ICT and the Internet we can discern the level of socioeconomic development of a nation and why Information and Communication Technologies allow economic growth. In the digital economy world, the use of ICT is important and necessary when incorporated into public administration.

In Ecuador within the Ministry of Telecommunications and the Information Society, the impact of Information and Communication Technologies is apparent in the level of productivity of the business sector. This growth is directly associated with production, but also other variables that directly affect the economic progress of the nation. Its effects intervene on investment, human capital as well as social, also on trade, and finally on innovation and entrepreneurship "(MINTEL, 2014). According to the IADB (Inter-American Development Bank), 10\% penetration of broadband services in the 
Region, is associated with an average increase of $3.2 \%$ of the Gross Domestic Product (GDP) and a rise in productivity of 2.6 percentage points, generating over 67,000 new employment positions.

In this context, ICT facilitation of communications, access to information via the Internet and assistance with social services of education, health, and electronic government has brought with it deep social, economic, and cultural transformations. Additional benefits are increased productivity and the emergence of virtual service economies, which contribute to economic, social, and cultural growth. The modernization of the State and distribution with equitableness through the development of local, national, and regional virtual platforms, ensure efficient participation in the digital economy.

The Internet is a tool for governance, for the transformation of the intersectional relations of society, and for the strengthening of its structures, in terms of use and of the development visions used at the moment in which virtual participation transits in a parallel with real participation (Albornoz, 2007), thus establishing the so-called e-government. This type of government with emphasis on electronic applications is focused towards activities related to human beings, such as e-information, ebusiness, e-learning, e-mail, e-health, etc.

On the other hand, ECLAC (United Nations Economic Commission for Latin America and the Caribbean) considers that the use of the resources provided by Information and Communication Technologies (ICT) is of great importance for strengthening and increasing the capacity of a government, in the achievement of its objectives and in the efficient provision of services to the citizen being essential (CEPAL, 2011). An electronic government with application of the ICT has its the main purpose to extend the government to the citizen, the company, the employee, and members of the operative team of the government itself; in order to inform, innovate, generate interaction, integrate and perform real-time transactions in a safe and timely method.

While it is true that the implementation of e-government (as an application of ICT) is used for the masses (conglomerate of people) in developed countries and gradually implemented in developing countries; it has not yet been clearly conceptualized and theoretically allows for evaluating its impact on public administration in a generic way. In spite of this, electronic government analogous to other applications based on ICT has many concepts depending on the perspective that both researchers and professional specialists need to define.

\section{THE DEVELOPMENT INDEX OF THE ELECTRONIC GOVERNMENT OF ECUADOR}

Through the incursion of Information and Communication Technologies, a new form of Digital Economy has developed. Statistical indicators at the level of the telecommunication development sector make it possible to compare the use of information technologies with respect to accessibility, allowing their results to formulate policies and strategies that favor the growth of said technologies, cohesion, social inclusion, in order to monitor their effects on the economic and social evolution of Ecuador (CEPAL, 2005). Twice a year, the United Nations Organization presents a report from the Ecuador government, which evaluates the telecommunication infrastructure, online services, and human talent, among others.

Ecuador, in relation to the Electronic Government Development Index (EGDI), measures the quality and scope of online services, telecommunications connectivity, and human capacity. This method of calculation represents the weighted average of these three most important dimensions of electronic administration. Ecuador obtained a 0.5625 score, improving substantially with respect to the average 0.5053 score of the Latin American countries as a whole in 2014, occupying eleventh place in the ranking of the Americas. International ranking (dynamic and growing) is subject to the efforts, policies and constancy of the government and the rest of the nations.

The aforementioned results are indicative of the effectiveness and efficiency of the GADs (local level management) of Ecuador, in relation to the access and use of ICT in the performance of the 
functions. Development of electronic government under this model allowed identification of more than $50 \%$ of local governments that have implemented applications providing up to date information for the citizenry, in a diversity of topics.

The maturity of the electronic government analyzed and evaluated through the model indicates that $60 \%$ of GADs advertise and provide basic information, while $48 \%$ of GADs allow one-way communication with the citizen, and only $28 \%$ of them allow communication in a double sense between the local government and the citizens. Only $6 \%$ of GADs have some transactional application, and there are not any applications in GAD that allow total interactivity with local public management.

All the exposed results demonstrate and show that the Ecuadorian local e-government is in an emerging phase of medium development, with information of interest to the citizen and with respect to compliance with the Organic Law of Transparency and Access to the Public Information. Therefore, it is necessary to design policies and programs that stimulate bi-directional communication with the citizens and additionally, the provision of public services online and the ability for payments of these in a secure manner.

\section{IMPLEMENTATION OF THE ELECTRONIC GOVERNMENT IN THE ECUADORIAN PUBLIC ADMINISTRATION}

At the summit held in El Salvador in October 2008 (Secretaría Nacional de la Administración Pública. Plan Nacional de Gobierno Electrónico 2014 - 2017), one of the resolutions stated that "governments are recommended to formalize and institutionalize authorities responsible for the development and consolidation of electronic government" (Iberoamerican e-government letter, section 22. 2008); this was in agreements with the Ibero-American countries to create simpler, more public and efficient government mechanisms.

Rafael Correa, President from 2007 to 2017, adopted measures for his transitional form of government to improve the living conditions of citizens, which were published in the National Plan of Good Living (Plan Nacional del Buen Vivir, 2013-2017). In Objective 11 of this document, it emphasized changes in the provision of public services to a digital format and, in this way, create universal access.

The creation of this universal access is supported by the constitution of the republic in its article 227 that highlights: "Public Administration is a service to the community that is governed by principles of efficiency, quality, hierarchy, de-concentration, decentralization, coordination, participation, planning, transparency and evaluation."

The implementation of electronic government in Ecuador was decreed by Presidential Bill \#149 on December 18, 2013. Two of the most important articles in the Bill are:

Art. 1.- Electronic government.- The implementation of electronic government in the Central Public Administration, Institutional and that depends on the Executive Function, which consists of the use of information and communication technologies by the entities to transform the relations with citizens, between government entities and private companies in order to improve the quality of government services to citizens, promote interaction with private companies, strengthen citizen participation through access to information and efficient government services and effective and contribute to transparency, participation and citizen collaboration.

Art. 5.- Simplification of procedures. - The central, institutional public administration that depends on the Executive Function will establish the management with a focus on the simplification of procedures. Public management will tend progressively to the reduction and elimination of the duplication of requirements and activities that the citizen must perform before the administration to access efficient, transparent and quality services.

The principle of this form of electronic government in Ecuador has begun with the document management system "QUIPUX". This program is a modified version of an earlier system based on a GNU license which uses open standards and technologies. The idea was to create a policy of "Zero 
Papers", an ambitious proposal for a Latin American country accustomed to an extensive paper trail. However this way, all procedures would have to be tracked and monitored with nightly server backup to realize success. In theory, it's a very interesting idea with inherently potential problems that have been presented so far.

\section{METHODOLOGY}

The research method used is based on the explanatory approach, through the documentary review of secondary sources, of research works such as "The Impact of Information Technology in Organizations," "The Impact of Information Technologies Information and Communication in the Operation of the Public Administration of Bogotá DC and its relationship with the citizen in the Education sector," "The impact of Information and Communication Technologies and the Regulatory Improvement in Citizen Attention," in addition to the review of Web pages related to Electronic Government.

\section{DISCUSSION}

Undoubtedly, technological changes have been positively impacted through technological development, bringing with it a break from the classical paradigm of governing, making it necessary to implement the Electronic Government, with all the advantages associated with it. Through this, we have to impact in a positive way, economic, social, and cultural growth.

By developing this type of government, the distribution of services for the citizen is achieved in an equitable manner. Since services can be accessed online, it allows for development of local, national, and regional virtual cooperation platforms, which ensures efficient participation in the global economy. Thanks to transparency in public management, administrative political processes are integrated for greater efficiency in the art of governing and greater transparency in public management.

However, it is necessary to take into account the possible disadvantages or threats that may be inherent within the optimal implementation of the technological changes represented in the electronic government platform. The disadvantages mentioned below could be avoided:

- Deficiency in the technological and physical infrastructure for the establishment of a specifically technical online government.

- Existence of illiterate technological citizens and the means to accommodate their needs.

- Lack of communication and coordination between the different Government agencies.

In such a way that the development of these new Information and Communication Technologies are changes that facilitate the management of governmental and non-governmental institutions, they give way to new forms of management or governing, as is the case of electronic government in such a way that achieve a benefit to society through better functioning and providing better services.

Electronic government is a current and important topic for the world, the region, and Ecuador. This is why there are regional, national, and local global organizations promoting the use and implementation of this tool. Among the main initiatives we can mention from the Organization of American States (OAS) with its RED GEALC (The Network of e-Government Leaders of Latin America and the Caribbean) program, the Institute for Connectivity in the Americas (ICA), the World Bank (LCR Regional Knowledge Management), the Inter-American Development Bank, the Department for Economic and Social Affairs of the United Nations (UNDESA), the Economic Commission for Latin America and the Caribbean (ECLAC) - these organizations together seek to highlight the importance of this application for the socio-economic development of a country.

In a survey conducted by the United Nations Organization on electronic government called "Egovernment for the future we want," Ecuador ranked 83 out of 193 countries worldwide. This sur- 
vey aimed at the development of information and communication technologies which were effective between state entities and communication with users.

From this point, the deficiencies that existed as a country with regard to electronic government were reinforced, and for this reason the creation of the "National Plan for Electronic Government" was established in 2014, which had clear objectives that were:

- Increase the provision and quality of online services.

- Increase access and transparency to public information. as a means to encourage citizen participation and collaboration in the work of the government.

- Increase the efficiency, effectiveness and performance of public entities.

However simple these objectives may seem, they caused a certain level of rejection by the citizenry, the first complaints being the idea of massive governmental surveillance and violation of privacy.

Furthermore, a percentage of the citizens do not have ready access to computers and internet service or the ability to carry out certain procedures online as the electronic government promotes. The ability to interface with technology might pose a stumbling block for some citizens.

Finally, for these institutions, the only permanent and positive thing is change for the betterment of emerging and developing countries. The public and private institutions of today must be evolving and changing, as those are necessary elements for the evolution and growth of their respective developments. We have analyzed that there are many areas in which societies and institutions evolve, but one of the areas that these changes are taking place is the technological area. Therefore, the technological changes involve constant changes in the way things are done.

Important question: Are institutions ready for this change? It is definitely not easy, since there are many elements and factors that can influence how easy or difficult it can be for an institution to get all hierarchical levels and all staff of these organizations to accept and adapt to the changes of these new technologies in their daily tasks.

\section{REFERENCES}

Albornoz, B. (2007). Experiencias andinas de gobierno electrónico: La problemática de la participación ciudadana [Andean experiences of electronic government: The problem of citizen participation]. Quito, Pichincha, Ecuador: B. A. Rivero, Ed.

Arteaga, A., Medellín, E., \& Santos, M. J. (1995). Dimensiones sociales del cambio tecnológico. Revista de Ciencias Sociales [Social dimensions of technological change. Social Sciences Magazine], 9-22.

CEPAL. (2005). Indicadores clave de las tecnologías de la información y de las Comunicaciones [Key technologies of information and communication indicators]. Santiago de Chile, Chile: Naciones Unidas.

CEPAL. (2011). El gobierno electrónico en la Gestión Pública [E-government in public management]. Santiago de Chile: Naciones Unidas.

Cobo, J. (2009). El concepto de tecnologías de la información. Benchmarking sobre las definiciones de las TIC en la sociedad del conocimiento [The concept of information technologies. Benchmarking on the definitions of ICT in the society of knowledge]. ZER revista de estudios de comunicacion, , 295-318.

De, R. O. S. (2013). Implementación del gobierno electrónico en la administración publica [Implementation of electronic government in public administration], 1-8.

Douglas, D. (2012). Foreword. In W. Bijker, T. Hughes, \& T. Pinch (Eds.), The social construction of technological systems: New directions in the sociology and history of technology. MIT Press. Retrieved from http://www.jstor.org/stable/i.ctt5virsq

Ecuador. Asamblea Constituyente. (2008). Constitución de la República del Ecuador 2008. Montecristi: Publicada en el Registro Oficial No. 449 - 20 de octubre de 2008.

Mejía, J., \& Muñoz, M. (2017). Tendencias en Tecnología de Información y Comunicación [Trends in Information and Communication Technology]. Revista Ibérica de Sistemas e Tecnología de Información, ix-xii. 
MINTEL. (2014). Tecnologías de la Información y Comunicaciones para el Desarrollo [nformation Technologies and Communications for Development]. Quito: Ministerio de Telecomunicaciones y de la Sociedad de la Información, Subsecretaría de Fomento de la Sociedad de la Información y Gobierno en Línea.

Parayil, G. (1991). Technological knowledge and technological change. Technology and Society, 289-304.

Pugh, E. W. (1995). Building IBM: Shaping and Industry and Its Technology. MIT Press, 24-27.

Sánchez, R. M. (2012). El teletrabajo como tendencia del mercado laboral [Teleworking as a labor market trend]. Retos $I I$.

Secretaría Nacional de la Administración Pública. (26 de mayo de 2014). Plan Nacional de Gobierno Electrónico 2014 - 2017 [National Plan for Electronic Government 2014 - 2017]. Versión 1.0. Quito, Pichincha, Ecuador.

Secretaría Nacional de Planificación y Desarrollo, "Plan Nacional Buen Vivir," [ National Good Living Plan]. Biblioteca Virtual SGR, consulta 27 de abril de 2018, http://biblioteca.gestionderiesgos.gob.ec/items/show/55.

Soto, E. S. (2012). El teletrabajo del siglo XXI [Teleworking in the 21st century]. In V. Q. Sáez, Ideas, tendencias y nuevas formas de trabajo para la economía del conocimiento (pp. 7-19). Roja: Gobierno de la Roja.

Woodward, J. (1955). Comportamiento Y Desarrollo Organizacional [Behavior and Organizational Development]. Essex: South-East Essex Technical College.

\section{BIOGRAPHY}

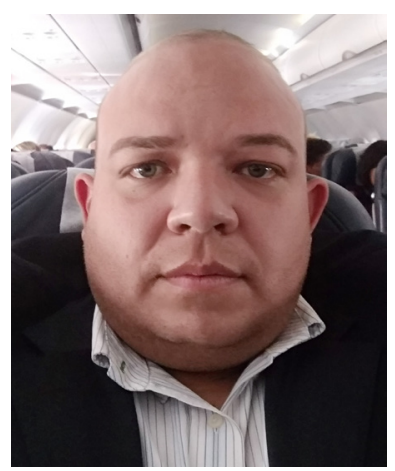

Josueth Meza hails from Quito Ecuador. At the beginning of 2019, I will be completing my PhD. studies in Management from the Central University of Venezuela. I have been teaching management, operations research, entrepreneurship and economic politics at the Universidad Central del Ecuador and Universidad Técnica del Norte. My Master's Degree was awarded in 2004 from Florida Metropolitan University (USA) after attending the same university for my undergraduate degree in 2002, all the while working full-time as a service tech and later as a community manager.

My love of teaching has inspired me to pursue a Doctorate in Management. Having lived in Ecuador for most of my life, I've seen the inefficiencies of my government and I wish to inspire my students to think 'outside the box' and develop new ideas for how to streamline governmental functions and apply these same methods to the future entrepreneurs attending my classes. 